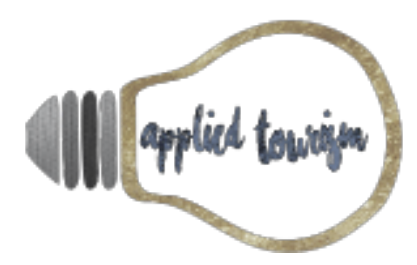

Volume 4, número 1, 2019, p. 01- 17

\title{
A PERCEPÇÃO DOS TURISTAS DE NEGÓCIOS SOBRE A COMUNICAÇÃO DA FEIRA FENAHABIT EM BLUMENAU/SC
}

Kathleen Karoline Brandt Silveira

Mestranda em Turismo e Hotelaria- UNIVALI

kathleenbs@hotmail.com

Camila Belli Kraus

Mestranda em Turismo e Hotelaria- UNIVALI

kmilabk@gmail.com

Isabela Belli Kraus

Mestranda em Turismo e Hotelaria- UNIVALI

belabelli@gmail.com

Sara Joana Gadotti dos Anjos

Doutora em Turismo e Hotelaria - UNIVALI

sara@univali.br

Recebido: 12 de fevereiro, 2018

Aprovado: 30 de maio, 2018

\section{RESUMO}

Considera-se o turismo de negócios como um aspecto potencial para o desenvolvimento local e regional de um destino, e a importância de proporcionar um excelente serviço aos visitantes, levando em consideração as estratégias de comunicação que devem ser projetadas para ajudar o destino a se comunicar de forma eficaz, desempenhando um papel vital no aumento da atratividade. Nesta temática, o artigo tem como objetivo analisar a percepção dos turistas de negócios sobre a comunicação da FENAHABIT e a hotelaria de Blumenau/SC. A metodologia aplicada foi de abordagem quantitativa. A realização da pesquisa ocorreu durante a feira, na qual, foram aplicados 31 questionários diretamente com os gestores de negócios. Os resultados obtidos apontam alguns fatores relevantes em relação a comunicação realizada pela feira em comparação com a percepção dos gestores de negócios, caraterizados pelo envolvimento, segurança e interação durante o evento.

Palavras-chaves: Turismo de negócios. Comunicação. Hotelaria. 


\section{INTRODUÇÃO}

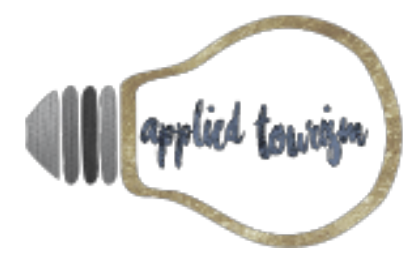

Volume 4, número 1, 2019, p. 01- 17

O turismo de negócios demonstra ser de grande interesse estratégico para o desenvolvimento turístico das regiões, especialmente aqueles com diferenciação de atrações turísticas (Marques \& Santos, 2016). Possui um alto rendimento de benefícios econômicos para economia, se analisarmos os resultados de turistas de negócios ao longo do ano (Weber \& Ladkin, 2005; Wang \& Davidson, 2010).

O turismo de negócios é um dos responsáveis pelo aumento do turismo urbano, principalmente no que se refere à construção de centros de convenções, construídos especificamente como parte de programas de desenvolvimento econômico. O estabelecimento de hotéis de negócios é visto como uma das manifestações físicas da economia global em locais geográficos particulares. Ao longo dos últimos anos tem sido registrado um forte crescimento nos fluxos de turismo de negócios em âmbito global, nacional e internacional (Rogerson, 2015).

Considera-se o potencial do Turismo de Negócios para o desenvolvimento local e regional e a importância de proporcionar um excelente serviço aos visitantes para garantir níveis elevados de satisfação durante a estadia no seu destino, que podem exceder as suas expectativas (Marques \& Santos, 2016).

Nos últimos anos foram realizados estudos na área, sendo alguns com metodologia empírica, que abordam os temas: Discutir questões negligenciadas à avaliação dos benefícios líquidos de um setor de MICE em expansão dentro de um destino turístico (Dwyer \& Forsyth, 1997). Estabelecer o progresso da comunicação com uma revisão de trabalhos publicados em revistas de turismo e hospitalidade entre 2009 e 2013 (Law, Buhalis \& Cobanoglu, 2014); Identificar considerações e questões-chave que afetam e são graves para estimativas confiáveis dos impactos econômicos de eventos empresariais e turismo de negócios (Kumar \& Hussain, 2014); Interrogar estudos existentes e as questões de pesquisa relacionadas à compreensão das mobilidades turísticas em desenvolvimento especificamente na região emergente de turismo da África (Rogerson, 2015); Entender que objetivos do investimento em marketing de mídia social é tão importante quanto aos investimentos tradicionais de marketing para a organização de serviços (Mills \& Plangger, 2015).

Outros estudos seguiram a metodologia qualitativa sendo eles dos seguintes temas: revisão das microanálises da despesa turística (Wang \& Davidson, 2010); Padrões comportamentais dos usuários da pesquisa de informações de turismo: de on-line para off-line (Ho, Lin \& Chen, 2012); Comunicação da CSR no ambiente online: evidência do setor de distribuição de turismo na Romênia (Moisescu, 2015); Ferramentas de comunicação de marketing e branding no posicionamento e na promoção da identidade dos destinos da Letônia (Voznuka, 2016). 


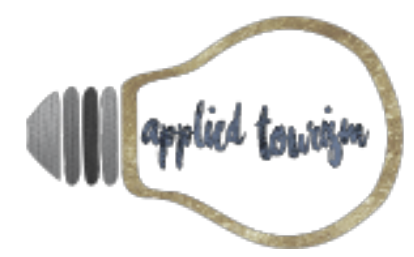

Volume 4, número 1, 2019, p. 01- 17

E também com metodologias quantitativas, com os seguintes temas: Pesquisa de informações turísticas e escolha de destino em uma era digital (Jacobsen \& Munar, 2012); Análise de fontes de informação do turismo usando uma perspectiva da escala de Mokken (Camprubí \& Coromina, 2016); Comportamento de pesquisa e risco perceptível de visitantes do parque (Li, Hunf, Cheng \& Petrick, 2016); Cidades Património da Humanidade da Espanha: A reputação online como um elemento de desenvolvimento do turismo (Márquez-González \& Caro Herrero, 2017).

Alguns outros estudos seguiram métodos diferentes, sendo o método Delphi com tema Desenvolvendo o turismo de negócios para além dos principais centros urbanos: as perspectivas dos interessados locais (Marques \& Santos, 2016) e com abordagem quali-quantitativa com tema, evidências sobre motivações de lazer de participantes da conferência (Tretyakevich \& Maggi, 2012).

Diante deste contexto, o presente estudo tem por objetivo: Analisar a percepção dos gestores de negócios sobre a comunicação da Feira Nacional das Tecnologias da Habitação e Imobiliário - FENAHABIT e a hotelaria de Blumenau/SC. Foram aplicados questionários diretamente com os gestores de negócios que estavam hospedados na cidade durante a 13a edição da FENAHABIT, que ocorreu entre os dias 25 a 28 de Maio de 2017, a qual, é considerada a maior feira imobiliária do sul do país.

A escolha do destino se deu em virtude da vasta receptividade de eventos de diversos segmentos que a cidade de Blumenau comporta ao longo do ano. Além de Blumenau ser localizada no centro do Vale do Itajaí, com fácil acesso ao litoral e oeste catarinense e possui excelente estrutura para turismo de negócios. Nesta edição 21.752 visitantes estiveram pela Vila Germânica. A feira teve a participação de 100 expositores de Blumenau e região e mais de 220 marcas nacionais e internacionais (Via Ápia Eventos, 2017).

\section{A COMUNICAÇÃO NO TURISMO}

O sucesso do destino depende da capacidade de desenvolvimento das estratégias de marketing planejadas, como em todos os aspectos da comunicação. As estratégias de comunicação são projetadas para ajudar o destino a se comunicar de forma eficaz, desempenhando um papel vital no aumento da atratividade de um destino de viagem (Voznuka, 2016).

A comunicação é uma importante estratégia para qualquer domínio empresarial (Moisescu, 2015). Pois, os visitantes desenvolvem uma imagem e expectativas sobre o destino baseadas em experiências anteriores, boca a boca, relatórios de imprensa, publicidade e crenças comuns, antes de visitar um destino, formando uma imagem 


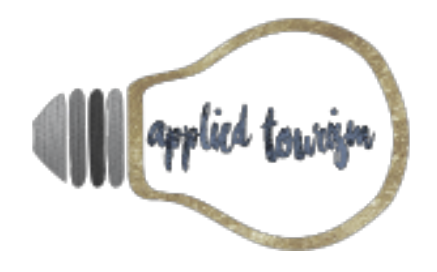

Volume 4, número 1, 2019, p. 01- 17

mental do destino por meio da sua interpretação motivada e emocional (Chon, 1992; Baloglu \& Brinberg, 1997; Konecnik, 2004; Kavoura \& Bitsani, 2013; Kiralova \& Pavliceka, 2015).

Tais comunicações podem ajudar o destino de diversas formas como: aumentar a conscientização do destino, alcançar publicidade global, fortalecer a imagem do destino para ser favorito, segmentar um mercado específico, assegurar a compreensão do que o destino faz, mudar o comportamento e as percepções quando necessário, apoiar a marca. Pode ainda, aumentar o número de visitas em canais de mídia social e/ou website, engajar partes interessadas e demonstrar o sucesso do destino, entre outras (Kiralova \& Pavliceka, 2015; Voznuka, 2016).

O benefício e eficácia para os destinos podem ser vistos no aumento da consciência da marca, engajamento da marca, boca a boca, amigos/gostos, confiança e validação social (Pergolino, Rothman, Miller \& Miller, 2012; Kiralova, 2014; Kiralova \& Pavliceka, 2015).

Portanto, é fundamental para o desenvolvimento do destino que as estratégias de comunicação sejam desenvolvidas de forma clara para melhor disseminação das mensagens e consequentemente engajamentos com os pretensos turistas.

Neste contexto, a comunicação online, também chamada de comunicação 2.0, eWOM ou reputação online do Turismo, permitiu que os sites passassem a ser mais dinâmicos, pois possibilitou que os usuários interajam e colaborem com as edições, bem como criem conteúdo e compartilhem experiências e também planejam suas viagens ao fazer consultas (Márquez-González \& Herrero, 2017).

A comunicação online foi uma transição de serviços, ou seja, dos meios tradicionais, para os meios online, e com isso, colocou desafios e oportunidades únicas para os comerciantes. Porém, muito importante é tratar todos os meios de canais online, em todas as plataformas (sejam desktops ou móveis) da mesma forma (Mills \& Plangger, 2015).

Os meios de comunicação online oferecem oportunidades para gerar relações mais sólidas, duradouras e conexões pessoais com os clientes já existentes, bem como potenciais clientes, permitindo assim, um novo meio tanto de retenção, quanto aquisição. As mídias online permitem um foco gerencial na construção e manutenção dos relacionamentos com os clientes (Dibb \& Meadows, 2001; Howcroft, Durkin, Armstrong \& Emerson, 2007; Mills \& Plangger, 2015).

Neste sentido, ao considerarmos o processo de planejamento de uma viajem, seja esta por diversos motivos, a busca por informações sobre o destino, hospedagens, atrativos, etc., é comum para o conhecimento do local. 


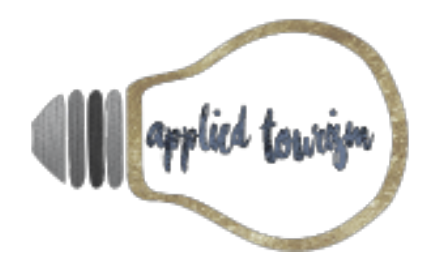

Volume 4, número 1, 2019, p. 01- 17

No entanto, as denominadas fontes de informação são compostas de fontes internas e externas (Jacobsen \& Munar, 2012). Fontes internas são dependentes de experiências e conhecimentos pessoais, até mesmo indicação de amigos e parentes. Já as fontes externas tendem a ser disponibilizadas pelo mercado, ou seja, são basicamente comerciais (Camprubi \& Coromina, 2016).

As pesquisas de informações sobre o turismo indicam que é iniciada pela busca interna recuperando as experiências pessoais anteriormente vivenciadas em um determinado destino específico ou um similar ao que se pretende visitar (Jacobsen \& Munar, 2012; Ho, Lin, \& Chen, 2012).

De um modo geral, tanto conhecimentos prévios e experiências de viagem têm um impacto inicial de busca de informações sobre o turismo. O conhecimento sobre o destino afeta o comportamento de pesquisa de informação turística e de tomada de decisão (Ho, et. al., 2012, Molina, Fernandez, Gómez \& Aranda, 2017).

O fato do turista não poder experimentar um serviço antes de adquiri-lo traz consideráveis incertezas ao processo de tomada de decisão. Embora a pesquisa de informações não garante a satisfação do consumo de experiências, o recolhimento de informações pode ajudar a reduzir os riscos percebidos dos turistas (Li, Hunf, Cheng \& Petrick, 2015).

A aquisição de informações online difere de seus formulários offline; informações compartilhadas através da Internet, especificamente tem influências reais no processo pelo qual as pessoas desenvolvem imagens e expectativas do destino escolhido (Jacobsen \& Munar, 2012; Llordà-Riera, Martínez-Ruiz, Jiménez-Zarco \& Izquierdo-Yusta, 2015; Camprubi \& Coromina, 2016).

A melhoria na tecnologia de informação e comunicação vem se transformando e alterando o comportamento de pesquisa online de informação sobre o turismo (Molina, Fernandez, Gómez \& Aranda, 2017).

\section{TURISMO DE NEGÓCIOS}

Mesmo que ao longo dos últimos anos tenha sido registrado um forte crescimento nos fluxos de turismo de negócios global, tanto nacional como internacionalmente, ele faz parte de uma pequena parcela de estudos quando analisamos o turismo como um todo. Além disso, estudos existentes sobre viagens de negócios e turismo é diversificado e altamente fragmentado (Rogerson, 2015).

O "turismo de negócios" pode ser dividido em pelo menos quinze categorias de viagens, incluindo viagens de negócios individuais em geral, cursos de treinamento, lançamentos de produtos e viagens corporativas e de 


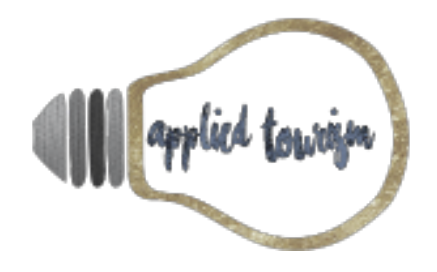

Volume 4, número 1, 2019, p. 01- 17

incentivo. No entanto, o setor é convencionalmente definido como 'viagens de negócios independentes', por um lado, e 'viajando para fins de reunião, incentivos, conferências e exposições', por outro lado (Rogerson, 2015).

O turismo de negócios é um dos responsáveis pelo aumento do turismo urbano, principalmente no que se refere à construção de centros de convenções, construídos especificamente como parte de programas de desenvolvimento econômico. É provável que o estabelecimento de hotéis de negócios seja visto como "uma manifestação física da economia da rede global em locais geográficos particulares" (Rogerson, 2015). No entanto, muitas viagens de negócios, às vezes incorporam um componente de lazer, o que significa que o desenvolvimento de serviços para viajantes de negócios, muitas vezes se agrega aos produtos turísticos voltados para os viajantes de lazer (Tretyakevich \& Maggi, 2012; Rogerson, 2015).

Alguns autores consideram que o turismo de negócios, mesmo implicando remuneração, refletem a utilização dos mesmos serviços e comodidades e, como tal, devem ser fechados no conceito global do turismo, dado que o turismo de negócios é muitas vezes transformado exclusivamente em turismo de lazer, especialmente quando existe uma extensão da estadia no destino além das obrigações profissionais (Boniface \& Cooper, 2009; Marques $\&$ Santos, 2016).

O turismo de negócios demonstra ser de grande interesse estratégico para o desenvolvimento turístico das regiões, especialmente aqueles com diferenciação de atrações turísticas (Marques \& Santos, 2016).

Turismo de negócios tem se tornado um importante sector econômico em muitas partes do mundo e desenvolvendo um importante papel no mercado global moderno (Dwyer \& Forsyth, 1997). Possui ainda um alto rendimento de benefícios econômicos para economia, se analisarmos os resultados de turistas de negócios ao longo do ano (Weber \& Ladkin, 2005; Wang \& Davidson, 2010;).

A receita gerada pelo turismo de negócios irá conduzir a mais oportunidades de trabalho, além de atrair mais eventos internacionais para o destino. Para servir os turistas de negócios na melhor forma é necessário fazer investimentos no desenvolvimento da infra-estrutura do destino, como hotéis, centros de convenções e aeroportos (Kumar \& Hussain, 2014).

Atualmente, o turismo de negócios tem um peso econômico importante nas economias locais e regionais e corresponde a um setor turístico com grande potencial de desenvolvimento (Marques \& Santos, 2016). 


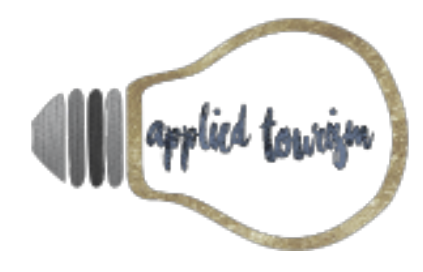

Volume 4, número 1, 2019, p. 01- 17

A baixa sazonalidade, o impacto ambiental controlado, a maior receita para alojamento e locais de encontro, a alta demanda de alimentos e bebidas (almoços, jantares de gala, coffeebreaks, etc.), o impulso nas atividades de lazer e a relativa resiliência à atual Crise econômica, são alguns dos principais fatores que tornam o turismo de negócios tão atraente para os destinos. Isto reflete o potencial do Turismo de Negócios para o desenvolvimento local e regional e a importância de proporcionar um excelente serviço aos visitantes para garantir níveis elevados de satisfação durante a estadia no seu destino, que excedem as suas expectativas (Marques \& Santos, 2016).

\section{METODOLOGIA}

Para alcançar o objetivo foram realizadas pesquisas exploratórias de abordagem quantitativa. Utilizou-se a abordagem exploratória por ser descrita como não-estruturada, exploratória e baseada em pequenas amostras. Ainda, buscou-se quantificar os dados e aplicar de alguma forma a análise estatística, pois ajuda a contextualizar e compreender os fenômenos sociais (Malhotra, 2001).

Foi realizado um levantamento survey com questionário para explorar, descrever e explicar um método lógico (Babbie, 1999). O instrumento de coleta de dados quantitativos seguiu o método de questionário semiestruturado, autopreenchível, com perguntas abertas e fechadas, baseado nos construtos dos autores Yoo \& Zhao (2010) (Turismo de negócios) e Yeh, Leong, Blecher \& Lai (2005) (Comunicação Hoteleira).

A coleta de dados foi realizada durante os quatro dias de feira. Nesta edição, haviam 45 stands de empresas de diversas cidades do Brasil, então, as entrevistas foram realizadas em 15 stands, e aplicados a todos os gestores de negócios presentes que estiveram hospedados na cidade durante o período. Os demais gestores dos stands e os visitantes foram excluídos da amostra, pois eram de cidades próximas da região de Blumenau, e em virtude disso, não estavam hospedados na cidade. Sendo assim a coleta de dados resultou em 31 questionários, representando 100\% da população.

\section{POPULAÇÃO E AMOSTRA}

Nesta edição da Fenahabit, haviam 45 stands de empresas que não possuíam cede na cidade de Blumenau, com isso, as entrevistas foram realizadas em 15 stands, e aplicados a todos os gestores de negócios presentes que estiveram hospedados em hotel ou pousada durante o período em que ocorria a feira, sendo que em alguns stands pesquisados, havia um ou mais gestores de negócios presentes. Os demais stands e gestores foram excluídos da amostra, pois eram de cidades próximas da região de Blumenau, e em virtude disso, não estavam hospedados na cidade, o mesmo ocorreu com os visitantes, visto que, não se enquadravam à proposta da pesquisa. 


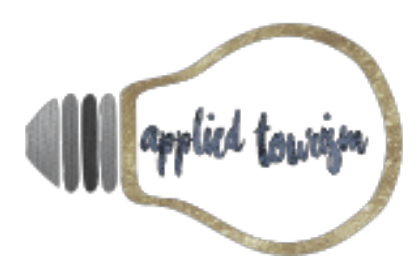

Volume 4, número 1, 2019, p. 01- 17

A coleta de dados ocorreu no período de 25 a 28 de maio de 2017 e resultou em 31 questionários respondidos, representando 100\% da população. Sendo assim, a amostra é composta por todos os gestores de negócios da feira que não residiam na cidade de Blumenau e estavam hospedados em hotel ou pousada durante a sua estadia na cidade. Para a análise qualitativa da pesquisa, realizou-se uma entrevista com um dos organizadores do evento.

\section{RESULTADOS}

\section{Característica da Amostra}

Este estudo, propôs analisar a comunicação utilizada pela organização da FENAHABIT, e comparar com a percepção dos gestores de negócios. Assim, a Tabela 01 destaca as variáveis sociodemográficas e o perfil dos gestores entrevistados, divididos em: Gênero, Faixa Etária, Classe Econômica, Ocupação Profissional e Formação Escolar.

Tabela 01: Características sociodemográficas dos gestores de negócios

\begin{tabular}{|c|c|c|c|}
\hline \multicolumn{2}{|c|}{ Características Sociodemográficas } & Frequência & Porcentagem \\
\hline \multirow{3}{*}{ Gênero } & Masculino & 22 & $70,97 \%$ \\
\hline & Feminino & 9 & $29,03 \%$ \\
\hline & Total & 31 & $100 \%$ \\
\hline \multirow{6}{*}{ Faixa Etária } & De 18 a 30 anos de Idade & 15 & $48,39 \%$ \\
\hline & De 31 a 40 anos de Idade & 12 & $38,71 \%$ \\
\hline & De 41 a 50 anos de Idade & 3 & $9,68 \%$ \\
\hline & De 51 a 60 anos de Idade & 1 & $3,23 \%$ \\
\hline & Mais de 60 anos de Idade & 0 & $0 \%$ \\
\hline & $\begin{array}{ll}\text { Total } \\
\end{array}$ & 31 & $100 \%$ \\
\hline \multirow{7}{*}{ Classe Econômica } & A & 3 & $9,68 \%$ \\
\hline & $\mathrm{B}$ & 2 & $6,45 \%$ \\
\hline & $\mathrm{C}$ & 10 & $32,26 \%$ \\
\hline & $\mathrm{D}$ & 7 & $22,58 \%$ \\
\hline & $\mathrm{E}$ & 6 & $19,35 \%$ \\
\hline & Prefere não responder & 3 & $9,68 \%$ \\
\hline & Total & 31 & $100 \%$ \\
\hline \multirow{3}{*}{ Ocupação Profissional } & Assalariados (as) & 20 & $64,52 \%$ \\
\hline & Empresários (as) & 8 & $25,81 \%$ \\
\hline & Autônomos (as) & 2 & $6,45 \%$ \\
\hline \multirow{2}{*}{ Ocupação Profissional } & Corretor de Imóveis & 1 & $3,23 \%$ \\
\hline & $\begin{array}{ll}\text { Total } \\
\end{array}$ & 31 & $100 \%$ \\
\hline \multirow{5}{*}{ Formação Escolar } & Fundamental Completo & 0 & $0 \%$ \\
\hline & Médio Completo & 3 & $9,68 \%$ \\
\hline & Superior Incompleto & 11 & $35,48 \%$ \\
\hline & Superior Completo & 10 & $32,26 \%$ \\
\hline & Pós-Graduado (a) & 7 & 22,58 \\
\hline
\end{tabular}




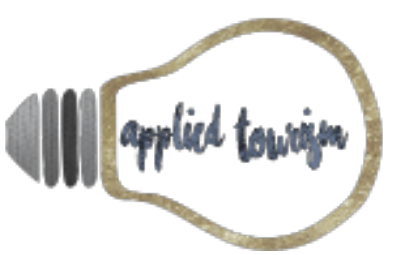

Volume 4, número 1, 2019, p. 01- 17

Fonte: Dados da pesquisa (2017)

aracterísticas Sociodemográficas

A amostra do estudo foi composta em sua maioria por homens (70,97\%), e 29,03\% de mulheres. Pessoas com a faixa etária de 18 a 30 anos (48,39\%), De 31 a 40 anos de Idade (38,71\%), De 41 a 50 anos de Idade (9,68\%), entrevistados com idade de 51 a 60 anos de Idade tiveram pouca representação (3,23\%) e indivíduos com mais de 60 anos não tiveram nenhuma participação. Em sua maioria, a amostra faz parte da Classe C (32,36\%), seguida da Classe D (22,58\%), Classe E (19,35\%), Classe A (9,68\%), Classe B (6,45\%) e 9,68\% da amostra preferiu não responder.

A ocupação profissional dos entrevistados foi composta por: Assalariados (64,52\%), Empresários (25,81\%), Autônomos (6,45\%) e Corretor de imóveis (3,23\%). Em relação à escolaridade, a amostra é composta em sua maioria por pessoas com o ensino superior incompleto $(35,48 \%)$, ensino superior completo $(32,26 \%)$, PósGraduados (22,58\%) e ensino médio completo (9,68\%).

Em relação a hospedagem dos entrevistados, a maioria ficou hospedada em algum hotel da cidade de Blumenau (90\%), porém uma pequena parcela se hospedou em pousada (10\%). Nenhum dos pesquisados optou por ficar em Hostel durante a sua estadia. Os hotéis e pousadas escolhidos para hospedagem foram: Ibis (26\%), IbisBudget (13\%), Mansiones (13\%), Steinhausen (13\%), Oásis Chartouni (10\%), Slaviero (10\%), Hospedaria Blumenau (6\%), St. John (6\%) e Pousada Vila Germânica (3\%).

Para melhor visualização dos resultados obtidos, a tabela 02 , demonstra a média de cada afirmação referente a temática de Turismo de Negócios adaptada do estudo de Yoo \& Zhao (2010).

Tabela 02: Afirmações e médias - Turismo de Negócios

\begin{tabular}{l|c}
\hline Afirmações e Médias - Turismo de Negócios & Média \\
\hline Q1 - Aprender novas habilidades e/ou conhecimentos & 3,77 \\
\hline Q2 - Oportunidades profissionais de networking & 3,90 \\
\hline Q3 - Interações pessoais com colegas ou amigos de trabalho & 4,09 \\
\hline Q4 - Procurar oportunidades de carreira & 2,93 \\
\hline Q5 - Ver pessoas que conheço em minha área de atuação & 3,29 \\
\hline Q6 - Acompanhar as mudanças no meu campo de trabalho & 3,77 \\
\hline Q7 - Oportunidades para visitar Blumenau & 3,64 \\
\hline Q8 - Oportunidades extras em Blumenau & 3,38 \\
\hline Q9 - Acessibilidade ao destino da Fenahabit & 3,93 \\
\hline Q10 - Oportunidade de escape do trabalho & 2,64 \\
\hline Q11 - Imagem atraente da cidade de Blumenau & 3,70 \\
\hline Q12 - Distância de viagem até Blumenau & 2,77 \\
\hline
\end{tabular}

Silveira, K. K. B.; Kraus, C. B; Kraus, I. B. \& Anjos, S. J. G. (2019). A PERCEPÇÃO DOS TURISTAS DE NEGÓCIOS SOBRE A COMUNICAÇÃO DA FEIRA FENAHABIT EM BLUMENAU/SC. Applied Tourism, 4(1), 01- 17. 


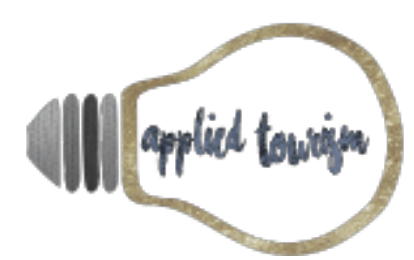

Volume 4, número 1, 2019, p. 01- 17

\begin{tabular}{l|c}
\hline Afirmações e Médias - Turismo de Negócios & Média \\
\hline Q13 - Experiência de viagens anteriores à Blumenau & 3,06 \\
\hline Q14 - Disponibilidade de tempo para participar da Fenahabit & 3,67 \\
\hline Q15 - Meu envolvimento com a feira & 4,45 \\
\hline Q16 - Segurança no local da feira & 4,22 \\
\hline Q17 - Qualidade da programação da feira & 3,58 \\
\hline Q18 - Duração da Fenahabit & 3,83 \\
\hline Q19 - Financiamento de viagem pela minha empresa & 3,64 \\
\hline
\end{tabular}

Fonte: Dados da pesquisa (2017)

Dentre as afirmações relacionadas ao turismo de negócios, é possível afirmar que os gestores de negócios da feira se sentem envolvidos com o evento $(4,45)$, se sentem seguros no local $(4,22)$ e que participar desse tipo de evento faz com que suas interações com colegas de trabalhos se torne mais pessoais do que dentro do ambiente de trabalho $(4,09)$.

Com as variáveis que obtiveram as menores médias é possível afirmar que os gestores de negócios não estão na feira em busca de oportunidades de carreira $(2,93)$, também não consideram o evento uma forma de escape do trabalho $(2,64)$. Bem como, não consideram que fizeram uma longa viagem até a cidade de Blumenau para participar da Fenahabit $(2,77)$.

Nota-se que a variável que se refere às oportunidades extras em Blumenau atingiu a média de 3,38, com isso podemos afirmar que os gestores de negócios da feira buscam outras coisas para fazer na cidade, além do evento.

A tabela 04, a seguir, expõe a média das afirmações apontadas pela amostra, relacionados a comunicação hoteleira adaptada do construto de Yeh, Leong, Blecher \& Lai (2005).

Tabela 04: Afirmações e médias - Comunicação Hoteleira

\begin{tabular}{l|c}
\hline Afirmações e Médias - Comunicação Hoteleira & Média \\
\hline Q29 - Site preciso, rápido e confiável para coletar informações e fazer reservas. & 3,74 \\
\hline Q30 - Acesso sem fio à Internet no hotel. & 4,25 \\
\hline Q31 - Computador para uso pessoal na área de convivência. & 2,80 \\
\hline Q32 - O hotel estar em redes sociais é muito importante quando eu escolho um hotel. & 3,96 \\
\hline $\begin{array}{l}\text { Q33 - Hotéis devem fornecer uma quantidade suficiente de e-commerce e serviços relacionados para } \\
\text { a satisfação e atendimento ao cliente }\end{array}$ & 4,16 \\
\hline $\begin{array}{l}\text { Q34 - Hotel deve fornecer informações precisas, rápidas e confiáveis no site de acordo com as } \\
\text { necessidades dos viajantes. }\end{array}$ & 4,38 \\
\hline Q35 - O hotel deve fornecer um site eficiente para obter vantagens competitivas no mercado. & 4,35 \\
\hline Q36 - Eu sempre obtenho um melhor preço em reservas pela Internet. & 4,06 \\
\hline $\begin{array}{l}\text { Q37 - A questão de segurança de Internet, informações pessoais ou número de cartão de crédito, } \\
\text { ainda é a minha principal preocupação para não efetuar a reserva on-line. }\end{array}$ & 3,54 \\
\hline
\end{tabular}




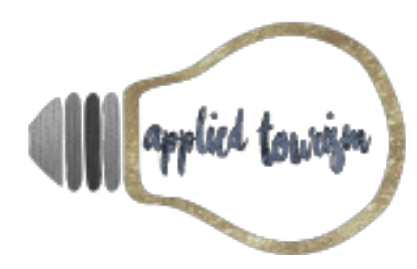

Volume 4, número 1, 2019, p. 01- 17

Q38 - Prefiro fazer minhas reservas por meio de um agente de viagens embora a Internet e sites estejam disponíveis e sejam populares.

Fonte: Dados da pesquisa (2017)

As afirmações que obtiveram as maiores médias em relação a comunicação hoteleira, revelam que a presença online é altamente necessária, visto que, as variáveis que tiveram maior representatividade são as relacionadas à internet.

Em relação às menores médias, pode-se perceber que os gestores de negócios não acham necessário que os hotéis possuam computadores disponíveis nas áreas de convivência. E não preferem fazer suas reservas por meio de um agente de viagens.

\section{DISCUSSÃO DOS RESULTADOS}

Com base na análise dos dados, se observa que, em alguns momentos, os dados obtidos na reaplicação da amostra foram semelhantes aos dados obtidos em outros estudos.

Em sua maioria, os gestores de negócios da Fenahabit afirmaram ter conhecimento sobre a feira por meio da sua empresa (56\%), Internet (35\%), outros meios (6\%) e Rede Social (6\%).

Em cada edição da feira, os organizadores realizam parceria com algum hotel da cidade, porém, 71\% dos entrevistados afirmaram não ter recebido nenhum tipo de indicação de hotel por parte dos organizadores da feira.

A maioria dos entrevistados (45\%) afirmou que o hotel e/ou pousada que estava hospedado não possuía nenhum tipo de informação sobre o evento, 29\% não soube dizer se o hotel sabia algo sobre a feira e apenas 26\% notou que o hotel possuía conhecimento sobre a feira.

O tempo de lazer e acessibilidade têm impulsionado o nível de renda para a população que está crescendo do setor do turismo (Kumar \& Hussain, 2014). No entanto, notou-se que a variável que se refere às oportunidades extras em Blumenau atingiu a média de 3,38, com isso podemos afirmar que os gestores de negócios da feira buscam outras coisas para fazer na cidade, além do evento. Corroborando com que muitas viagens de negócios, às vezes incorporam um componente de lazer e muitas vezes se agrega aos produtos turísticos voltados para os viajantes de lazer (Tretyakevich \& Maggi, 2012; Rogerson, 2015).

Dentre as afirmações relacionadas ao turismo de negócios, é possível afirmar que os gestores de negócios da feira se sentem envolvidos com o evento (4,45), essa afirmação é apoiada por Cohen (1974) e Uriely (2001), 


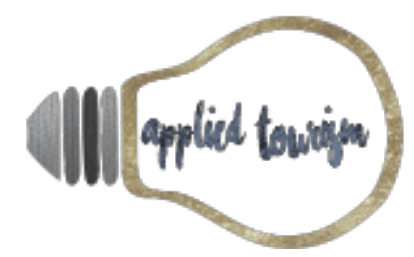

Volume 4, número 1, 2019, p. 01- 17

sugerindo que os profissionais que combinam negócios e viagens são mais propensos a viajar a trabalho em vez de trabalhar para viajar.

Outras médias que se destacaram são as relacionadas à cidade de Blumenau, como Oportunidade para visitar Blumenau (3,64), Imagem atraente da cidade de Blumenau (3,70) e também a variável que aborda a disponibilidade de tempo para participar da Fenahabit $(3,67)$. Por meio dessas afirmações, nota-se que os participantes da feira optaram por participar da feira por sentirem vontade de ir até o destino, e com isso aproveitar a oportunidade de trabalho para conhecê-lo. Isso vai de encontro que os autores Yoo \& Zhao (2010) identificaram em seu estudo, onde afirmam que o comparecimento às convenções de associação é bastante discricionário, é provável que os participantes potenciais escolham uma convenção específica que eles possam dar ao luxo de atender ao dinheiro e ao tempo.

Destaca-se também à média relacionada as oportunidades de networking $(3,90)$, que demonstra que os gestores de negócios aproveitam a feira para conhecer novas pessoas que trabalham no mesmo ramo de atuação para ampliar seus contatos. Isso vai de encontro ao que os autores Yoo \& Zhao (2010) afirmam em seu estudo, que o desejo de ampliar a rede profissional está crescendo tão rápido quanto o desemprego, e as pessoas estão se esforçando para encontros significativos. A rede bem-sucedida oferece vários resultados profissionais, tais como oportunidades de emprego, obtenção de informações, visibilidade, conselhos de carreira, amizade e recursos.

As demais médias em relação a comunicação hoteleira que se destacam são relacionadas a internet e tecnologia da informação, como Check-in e/ou check-out express (via internet ou aplicativo) (3,64). Está de acordo com o estudo realizado por Yeh et. al. (2005), os autores apontam que tendências futuras do e-commerce e aplicativos de TI na indústria de hospitalidade estão cada vez mais importantes, pois os clientes de hoje estão mais exigentes em relação ao acesso à Internet, por exemplo, check-in e check-out automático.

A média referente a "questão de segurança de Internet, informações pessoais ou número de cartão de crédito, ainda é a minha principal preocupação para não efetuar a reserva on-line" $(3,54)$ e "Prefiro fazer minhas reservas por meio de um agente de viagens embora a Internet e sites estejam disponíveis e sejam populares". $(2,09)$, justifica-se na afirmação de (Burgess, 2000; Lang, 2000) que revela os usuários de Internet ainda preferem reservar os seus planos de viagem por meio das agências de viagens devido à questão de segurança e a necessidade de um serviço pessoal e interface humana. Em termos da perspectiva do cliente, algumas das lacunas da Internet que causam a hesitação dos viajantes a utilizar a Internet para reservar o seu hotel e a passagem aérea são a privacidade e a segurança dos dados (Connolly, Olsen, \& Moore, 1998; Van Hoof, Ruys, \& Combrink, 1999; Lang, 2000; Jeong \& Lambert, 2001). 


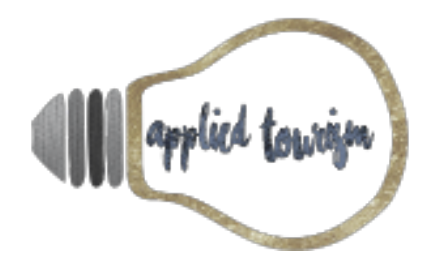

Volume 4, número 1, 2019, p. 01- 17

Existem outros dilemas que afetam a disponibilidade dos clientes para comprar produtos online. Os clientes não conseguem localizar os websites e informações que exigem, fator tempo, a sobrecarga de informações, desvantagens em termos de custos, a falta de confiança na tecnologia e a falta de uma interface humana (Lang, 2000). Esta afirmação corrobora com a média referente à variável "Hotéis devem fornecer uma quantidade suficiente de e-commerce e serviços relacionados para a satisfação e atendimento ao cliente" (4,16). Pois quanto maior a quantidade de e-commerces o hotel possuir online, menos tempo o possível cliente gastará procurando as informações que precisa.

\section{CONSIDERAÇÕES FINAIS}

Este estudo teve como objetivo analisar a percepção dos gestores de negócios sobre a comunicação da FENAHABIT e a hotelaria de Blumenau/SC. Com os resultados obtidos pela pesquisa constataram-se que no geral o público participante como expositor da Feira Nacional das Tecnologias da Habitação e Imobiliário é composta por homens, com de faixa etária de 18 a 30 anos, pertencentes da Classe C, são funcionários assalariados, e possuem ensino superior completo e incompleto.

No geral os entrevistados optaram em não ficar hospedados no hotel parceiro da Feira, optando por uma hospedagem mais próxima do local do evento. Sendo que deste, 90\% hospedou-se em hotel e uma pequena parcela em pousada 10\%. Dentre as opções de hotéis que a cidade dispõe, o mais utilizado foi a rede de Hotéis Accor (Bandeira Ibis ou Ibis Budget).

Nota-se também que os gestores de negócios da feira se sentem envolvidos com o evento, seguros em participar desse tipo de evento faz com que suas interações com colegas de trabalhos se torne mais pessoais do que no próprio ambiente de trabalho.

No geral, como haviam muitos empresários e donos de empresa participando como gestores de negócios da feira, notou-se que em sua maioria os respondentes não estavam na feira em busca de oportunidades de carreira e também não consideram o evento uma forma de escape do trabalho.

Nota-se que referente às oportunidades extras em Blumenau, os gestores de negócios buscam outras coisas para fazer na cidade, além do evento. Porém, não houve nenhum tipo de divulgação de pontos turísticos da cidade por parte da organização do evento.

Constatou-se a importância da presença online da divulgação da feira, sendo altamente necessária, visto que, as variáveis que tiveram maior representatividade na divulgação são as relacionadas à internet. 


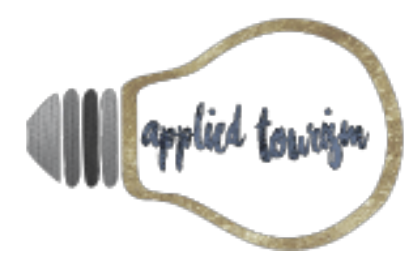

Volume 4, número 1, 2019, p. 01- 17

Além disso, a partir dos resultados obtidos com a pesquisa, considera-se que em relação ao turismo de negócios, os gestores de negócios têm conhecimento sobre a feira por meio da empresa em que trabalha, assim como a organização do evento se posiciona neste tipo de divulgação.

As limitações do estudo foram principalmente o baixo número da amostra, que se deu em virtude da dificuldade em se aplicar a pesquisa com gestores de negócios que não estavam hospedados no município de Blumenau.

Para futuros estudos pode-se considerar a replicação da pesquisa em demais eventos, com a adequação ou adaptação de escalas diferentes e, com foco no público de turismo de negócios e turistas a fim de comparar o desenvolvimento do destino.

\section{REFERÊNCIAS}

Babbie, E. R. (1999). Métodos de pesquisas de survey. Belo Horizonte: Ed. UFMG.

Baloglu, S.; \& Brinberg, D. (1997). Affective Images of Tourism Destinations. Journal of Travel Research, 35(4), 11-15.

Boniface, B., \& Cooper, C. (2009). Worldwide destinations casebook. The geography of travel and tourism (pp. 45-251).

Burgess, C. (2000). The hotel financial manager-challenges for the future. International Journal of Contemporary Hospitality Management, 12(1), 6-12.

Camprubí, R.; \& Coromina, L. (2016). Analysis of tourism information sources using a Mokken Scale perspective. Tourism Management, V. 56. 75-84.

Chon, K. S. (1992). Self-Image/Destination Image Congruity. Annals of Tourism Research, 19(2), 360-363.

Cohen, E. (1974). Who is a tourist? A conceptual clarification. Sociology, 22(4), 527-555.

Connolly, D. J., Olsen, M. D., \& Moore R. G. (1998). The Internet as a distribution channel. Cornell Hotel and Restaurant Administration Quarterly, 39(4), 42-54.

Dibb, S., \& Meadows, M. (2001). An application of a relationship marketing perspective in retail banking. The Service Industries Journal, 21(1), 169-194.

Dwyer, L., \& Forsyth, P. (1997). Impacts and benefits of MICE tourism: a framework for analysis. Tourism Economics, 3(1), 21-38.

Ho, C.I.; Lin, M.H.; \& Chen, H. M. (2012). Web users' behavioural patterns of tourism information search: from online to offline. Tourism Management, Vol. 33 No. 6, pp. 1468-1482. 


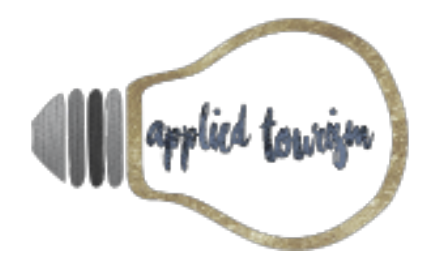

Volume 4, número 1, 2019, p. 01- 17

Howcroft, B., Durkin, M., Armstrong, G., \& Emerson, E. (2007). Small business-bank relationships and the role of internet banking. The Service Industries Journal, 27(7), 947-961.

Jacobsen, J. K. S., \& Munar, A. M. (2012). Tourist information search and destination choice in a digital age. Tourism Management, 1, 39-47.

Jeong, M., \& Lambert, C. U. (2001). Adaptation of an information quality framework to measure customers' behavioral intentions to use lodging Web sites. International Journal of Hospitality Management, 20(2), 129-146.

Kavoura, A.; \& Bitsani, E. (2013) E-branding of Rural Tourism in Carinthia, Austria. Tourism, An International Interdisciplinary Journal, 61, 289-312.

Kiralova, A. (2014). Social Media as a Tool of Tourism Destinations Marketing Campaign. IDIMT2014 Networking Societes-Cooperation and Conflict. 22nd Interdisciplinary Information Management Talks, 163-173.

Kiralova, A.; \& Pavliceka (2015). A. Development of social media strategies in tourism destination. Procedia-Social and Behavioral Sciences, 175, 358-366.

Konecnik, M. (2004). Evaluating Slovenia's Image as a Tourism Destination: A Self Analysis Process Towards Building a Destination Brand. Journal of Brand Management, 11(4), 307-316.

Kumar, J., \& Hussain, K. (2014). A Review of Assessing the Economic Impact of Business Tourism: Issues and Approaches. International Journal of Hospitality and Tourism Systems, 7(2), 49-55.

Lang, T. C. (2000). The effect of the Internet on travel consumer purchasing behavior and implications for travel agencies. Journal of Vacation Marketing, 6(4), 368-385.

Law, R., Buhalis, D., \& Cobanoglu, C. (2014). Progress on information and communication technologies in hospitality and tourism.International Journal of Contemporary Hospitality Management, Vol. 26 No. 5, pp. 727-750

Li, X. R., Hunf, K., Cheng, C., \& Petrick, J. F. (2016). Park Visitors' Perceived Risk and Information Search Behavior. Tourism Travel and Research Association: Advancing Tourism Research Globally. 60.

Llordà-Riera, I., Martínez-Ruiz, M. P., Jiménez-Zarco, A. I., \& Izquierdo-Yusta, A. (2015). A multidimensional analysis of the information sources construct and its relevance for destination image formation. Tourism Management, V. 38, 319-328.

Malhotra, N. K. (2001). Pesquisa de Marketing. 3. ed. Porto Alegre: Bookman. 


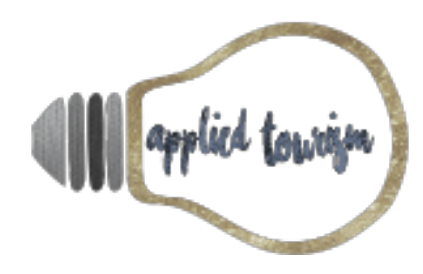

Volume 4, número 1, 2019, p. 01- 17

Marques, J., \& Santos, N. (2016). Developing business tourism beyond major urban centres: the perspectives of local stakeholders. Tourism and Hospitality Management, 22(1), 1-15.

Márquez-González, C. \& Caro Herrero, J. L. (2017). Ciudades Patrimonio de La Humanindad de España: La reputación online como elemento de desarrollo turístico. Pasos: Revista De Turismo y Patrimonio Cultural, v. 15(2), 437-457.

Mills, A. J. Plangger, K. (2015). Social media strategy for online service brands.Service Industries Journal. V. 35(10), p. 521-536.

Moisescu, O. I. (2015). Communicating CSR In The Online Environment: Evidence Fron The Romanian Tourism Distribuition Sector. Tourism \& Hospitality Management. V. 21(1), p. 79-94.

Molina, A., Fernandez, A. C., Gómez, \& Aranda, E. (2017). Differences in the city branding of European capitals based on online vs. offline sources of information. Tourism Management, V. 58, p. 28-39.

Neves, J. L. (1996) Pesquisa Qualitativa: Características, usos e possibilidades. Caderno de Pesquisas em Administração, São Paulo, 1:3, 1-5.

Pergolino, M, Rothman, D., Miller, J. \& Miller, J. (2012). The Definitive Guide to Social Marketing. A Marketo Workbook. Recuperado 21 de junho de 2017, de http://www.slideshare.net/ntdlife/definitive-guidetosocialmarketing-32648238 .

Rogerson, C. M. (2015). Unpacking business tourism mobilities in sub-Saharan Africa. Current Issues in Tourism, 18 (March), 44-56.

Tretyakevich, N., \& Maggi, R. (2012). Not just for business: some evidence on leisure motivations of conference attendees. Current Issues in Tourism, 15 (4), 391-395.

Uriely, N. (2001). 'Travelling workers' and 'working tourists': Variations across the interaction between work and tourism. International Journal of Tourism Research, 3, 1-8.

Van Hoof, H. B., Ruys, H. F., \& Combrink, T. E. (1999). Global hoteliers and the Internet: Use and perceptions. International Journal of Hospitality Information Technology, 1(1), 45-61.

Via Ápia Eventos. (2017): 21,7 mil pessoas visitaram a Fenahabit. Recuperado 08 de agosto de 2017, de http://www.viaapiaeventos.com.br/2017/05/28/217-mil-pessoas-visitaram-afenahabit.

Via Ápia Eventos. (2017): Fenahabit. Recuperado 09 de agosto de 2017, de http://www.viaapiaeventos.com.br/feirafenahabit.

Voznuka, J. (2016). Tools of marketing communications and branding in positioning and in promotion the identity of Latvia destinations. Journal Of Tourism \& Services, v. 7(13), p. 44-60. 


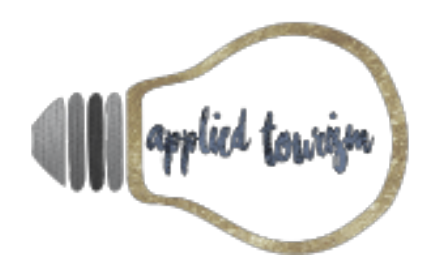

Volume 4, número 1, 2019, p. 01- 17

Wang, Y., \& Davidson, M. C. G. (2010). A review of micro-analyses of tourist expenditure. Current Issues in Tourism, 13(6), 507-524.

Weber, K., \& Ladkin, A. (2005). Trends Affecting the Convention Industry in the 21st Century. Journal of Convention \& Event Tourism, 6(4), 47-63.

Yeh, R. J., Leong, J. K., Blecher, L., \& Lai, H. H. S. (2005) Analysis of Hoteliers' E-Commerce and Information Technology Applications: Business Travelers' Perceptions and Needs. International Journal of Hospitality \& Tourism Administration, Vol. 6(2).

Yoo, J. J. \& Zhao, X. (2010) Revisiting Determinants of Convention Participation Decision Making, Journal of Travel \& Tourism Marketing, 27:2, 179-192. 